\title{
Cultivar la excepción: monstruosidad discursiva en Nietzsche
}

\section{Cultivating the Exception: discursive Monstrosity in Nietzsche}

\author{
Alonso Zengotita \\ Universidad de Buenos Aires, Argentina \\ alonsozengotita@gmail.com
}

Resumen: El tema de la construcción discursiva en Nietzsche se ha trabajado numerosas veces, pero prácticamente de modo exclusivo desde el lugar del lenguaje, articulado a las nociones de verdad, metáfora, memoria, mentira, conciencia, entre otros.

Sin tomar de modo central a la noción de lenguaje, en el presente artículo se buscará trabajar la forma en que la discursividad en Nietzsche se construye articulándola al modo en que la figura del genio es pensada. Dicho de otro modo, así como el genio aparecerá como excepcionalidad monstruosa, se buscará dar cuenta de cómo la discursividad nietzscheana presenta la misma caracterización frente a la epistemología canónica, aquella que Nietzsche busca confrontar. En orden de realizar esto, en primer lugar, se desarrollará cómo Nietzsche piensa al genio como excepción, para luego dar cuenta del lugar diferencial que dicha excepción ocupa respecto de la perspectiva biológica canónica con la que confronta: aquella de Darwin. Desde aquí, desplegando la modalidad de construcción discursiva nietzscheana, se buscará fundamentar cómo y desde qué dinámica ese discurso aparece como monstruosidad excepcional respecto a la epistemología predominante de su época. 
Palabras clave: Nietzsche, genio, discurso, construcción, monstruosidad.

Abstract: The subject of discursive construction in Nietzsche has been worked on numerous times, but practically exclusively from the place of language, articulated to the notions of truth, metaphor, memory, lies, conscience, among others.

Without taking the notion of language centrally, this article will seek to work on the way in which discursivity in Nietzsche is constructed by articulating it to the way in which the figure of genius is thought. In other words, just as the genius will appear as a monstrous exceptionality, it will be sought to account for how Nietzschean discursiveness presents the same characterization in the face of canonical epistemology, the one that Nietzsche seeks to confront. In order to do this, in the first place it will be developed how Nietzsche thinks of the genius as an exception, to then give an account of the differential place that said exception occupies with respect to the canonical biological perspective with which it confronts: that of Darwin. From here, by deploying the Nietzschean discursive construction modality, we will seek to establish how and from what dynamics this discourse appears as an exceptional monstrosity with respect to the predominant epistemology of its time.

Keywords: Nietzche, Genius, Discourse, Construction, Monstrosity.

Recibido: I 8 de agosto de 2020

Aceptado: I5 de abril de 2021 https://dx.doi.org/IO.I 5 I 74/rv.v I 4i29.566 


\section{Introducción}

E tema de la construcción discursiva en Nietzsche se ha trabajado numerosas veces, pero prácticamente de modo exclusivo desde el lugar del lenguaje. Se lo ha abordado desde el análisis del concepto de verdad como en los casos clásicos de Gemes (1992), Strong (1976) o Ansell-Pearson (1992), y más contemporáneamente en Álvarez y Ridley (2005), Rawat (2013), Yadin (2001) o Steineger (2004), por hacer mención de algunos. Asimismo, y siempre desde el lenguaje, se la articula con otras nociones fundamentales.

Lucero (2007) aborda la articulación entre música y lenguaje, a partir de la cual analiza el concepto de sujeto y sus tipologías en Nietzsche. Rivas (2008) relaciona mentira y metáfora para dar cuenta de la noción de cultura; Hanza (2003) trabaja la relación entre literatura y metáfora. Emden (2005) analiza en su libro los diversos entrecruces que se dan en la obra de Nietzsche entre cuerpo, lenguaje y conciencia a través de la cultura, la metáfora y la memoria; también sobre esa miríada conceptual y sus articulaciones con el lenguaje trabajan Barcalett Pérez (2006), Vattimo (2002), Onfray (2012), Reginster (2006), Stiegler (2003 y 2001), Drivet (2015), Sokel (2005), Assoun (2008), Gerhardt (2002), entre otros.

La discursividad nietzscheana y lo lingüístico son pensados asimismo desde la manera que el propio lenguaje de Nietzsche va modificándose a lo largo de sus escritos; se han producido así diccionarios de temas y términos, como el de Niemayer (2012), que incorpora análisis críticos terminológicos, o el de Van Tongeren (2001), como parte del Nietzsche Research Group.

Sin tomar de modo central a la noción de lenguaje, en el presente artículo se buscará trabajar la forma en que la discursividad en Nietzsche se construye articulándola al modo en que la figura del genio es pensada. Dicho de otro modo, así como el genio aparecerá como excepcionalidad monstruosa se buscará dar cuenta de 
cómo la discursividad nietzscheana presenta la misma caracterización frente a la epistemología canónica, aquella que Nietzsche busca confrontar.

En orden de realizar esto, primero, se desarrollará cómo Nietzsche piensa al genio como excepción, para luego dar cuenta del lugar diferencial que dicha excepción ocupa respecto de la perspectiva biológica canónica con la que confronta: aquella de Darwin. Desde aquí, desplegando la modalidad de construcción discursiva nietzscheana, se buscará fundamentar cómo y desde qué dinámica ese discurso aparece como monstruosidad excepcional respecto a la epistemología predominante de su época.

\section{El genio: fragilidad y autopotenciación vital}

Nietzsche caracteriza a la enfermedad de una manera específica:

La contraposición de las pasiones, la duplicidad, la triplicidad, la multiplicidad de las 'almas en un único pecho': ${ }^{1}$ muy insano, ruina interna, disgregante, delatando e intensificando una disensión y un anarquismo internos-: a no ser que una pasión finalmente acabe por dominar. Retorno de la salud - (2008: 14 [157], 584).

Que la salud implique el dominio de una pasión -de una fuerza- por sobre las otras, ¿supone una unificación completa de la interioridad, una desaparición de la multiplicidad?

La pasión dominante, la cual lleva consigo incluso la forma suprema de la salud en general: aquí se alcanza de manera óptima la coordinación de los sistemas internos y el concurso de sus trabajos

${ }^{1}$ Alusión al libro I del Fausto de Goethe. 
al servicio de una unidad - pero, ¡esto es prácticamente la definición de la salud! (Nietzsche, 2008: 14[157], 584).

La salud no implica entonces una desaparición de lo múltiple, sino su coordinación en función de una perspectiva rectora producto de la imposición de una pasión - una fuerza- a partir de la lucha interna.

En función de la vida ascendente, la relación entre enfermedad y salud es concebida de una determinada manera:

Desde ahora rige en Europa el destino de que precisamente sus hijos más fuertes alcancen tarde y rara vez su primavera -de que en su mayoría perezcan ya jóvenes, hastiados, ateridos, ensombrecidos, [...] ¡y no serían los más fuertes si no hubiesen sido también los más desilusionados! Porque esta es la prueba de su fuerza: sólo saliendo de toda la enfermedad de la época tienen que llegar a su salud (Nietzsche, 2008: 6[24], 183).

La fuerza de aquellos más fuertes no implica simplemente un estado de no disgregación interna, sino el haber atravesado con éxito dicho estado; aquellos que presentan la 'gran salud' (Große Gesundheit) no son aquellos que no se han enfermado sino quienes han superado la enfermedad. Sin embargo, existe también una excepción que excede, rompe, supera aquella en términos de ascendencia: la del genio.

Así caracteriza Nietzsche las acciones que Julio César ejercía sobre sí mismo:

Los medios con que Julio César se defendía de su constitución enfermiza y del dolor de cabeza: marchas enormes, género de vida sencillo, permanencia ininterrumpida al aire libre y constantes 
fatigas: ésas son, hablando a grandes rasgos, las condiciones de conservación del genio en general (2008: 11 [79], 390).

En primer plano aparece el cuerpo: un cuerpo tendiente a la enfermedad -o más bien, enfermo en sí- que se presenta como una amenaza frente a la que ha de haber una defensa. ${ }^{2}$ Las medidas impuestas - la perspectiva impuesta- de modo constante a la enfermedad que es su cuerpo es lo que produce "las condiciones de conservación del genio en general”; este carácter particular del genio es lo que lleva a Nietzsche a afirmar:

Contra la doctrina de la influencia del milieu y de las causas externas: la fuerza interna es infinitamente superior; mucho de lo que parece influencia del exterior es sólo su adecuación desde el interior. Exactamente los mismos milieus pueden interpretarse y utilizarse de manera contrapuesta: no hay hechos. -Un genio no es explicable dese estas condiciones de surgimiento (2008: 2 [175], 130).

El genio no se puede explicar desde una influencia determinante externa en tanto resulta un epítome del empoderamiento interno, en tanto es solo desde sus propias fuerzas - desde su particular dinámica creativa como continua lucha interna- que puede ser concebido.

${ }^{2}$ De hecho, los dos genios que mayormente nombra Nietzsche son el propio César y Napoleón, ambos tipos físicos no superlativos. No hay que olvidar asimismo dentro de la lista de nombramientos nietzscheana al propio Nietzsche y a su estado de salud; como señala Cragnolini (1998), "[e]n este sentido, Nietzsche mismo representa la paradoja del intento de una voluntad fuerte en un cuerpo en extremo débil" (130). Para lecturas que articulan la salud de Nietzsche a su obra cfr. Pérez Bacarlett (2006) o los clásicos de Halévy (1943) y Lichttemberger, (1923). 
Ahora bien, en tanto en el genio lo enfermo -esos destellos que entran en lucha constante, esa multiplicidad anárquica- es el cuerpo mismo, se imposibilita así el 'atravesar la enfermedad' para salir de ella y, por tanto, el ingresar en un circuito de producción de la 'gran salud'. La relación no es de transposición -un atravesar la enfermedad, para luego salir de ella en la forma de la 'gran salud'- sino de yuxtaposición: enfermedad y salud se yuxtaponen en la totalidad de la superficie que es el cuerpo. Así la configuración vital, a través de una ininterrumpida conflictividad interna, se halla en continua transformación; el propio cuerpo del genio -en tanto implica una voluntad de poder- es un motor continuo de acrecentamiento de fuerzas: el carácter pleno de la Wille zur Macht en tanto autosuperación (Selbstüberwindung), mostrado en el proceso económico extremo del configurar una continua tendencia disgregante, conformándola saludablemente en una determinación única. ${ }^{3}$

Ahora bien, Nietzsche afirma:

La voluntad de poder sólo puede exteriorizarse ante resistencias [...]. La apropiación e incorporación es sobre todo un querer subyugar, un formar, configurar y reconfigurar hasta que finalmente lo sometido ha pasado totalmente al poder del atacante y lo ha acrecentado. - Si esta incorporación no tiene éxito, la formación probablemente se desintegra (2008: 9[151], 282).

Desde la propia enfermedad que es el cuerpo, el genio se halla en permanente riesgo de desintegración: no existe un punto en el cual 'lo sometido ha pasado totalmente al poder del atacante', se debate, en la forma de la lucha, entre lo propiamente débil y la

3 "Napoleón como tipo completo, enteramente desarrollado de un instinto único [...] la concepción sencilla y el desenvolvimiento ingenioso de un solo motivo o de un corto número de ellos" (Nietzsche, 1999: 105). 
capacidad genial. En términos de "una doctrina que es un abismo: conserva el tipo superior y el inferior (destruye el intermedio)" (Nietzsche, 2008: 5[61], 162), el genio representa propiamente a ese abismo en sí mismo: el más bajo y el más alto en lucha, sin posibilidad de intermedios. Esta economía de fuerzas descentra, desquicia, desnivela la economía propia de la 'gran salud' al intensificarla al máximo: su capacidad autopotenciadora se da en términos de necesidad; las medidas de salud que toma César autotransformadoras- son necesarias para su propia conservación, para la conservación del genio en general. Así, correlativamente a la yuxtaposición de salud y enfermedad, se produce en el genio la yuxtaposición de conservación y aumento vital: ese cuerpo y esa voluntad configuran un tipo del continuo devenir ascendente, frente al constante riesgo de la disgregación total. "El 'genio' es la máquina más sublime que hay, -es, por consiguiente, la más frágil" (Nietzsche, 2008: 14 [133], 569). En ese peligro que implica el continuo batallar con sus debilidades el riesgo no es ya requisito para un carácter expansivo, sino para la propia conservación vital: es una máquina creativa justamente en tanto es frágil, en tanto en su propio existir siempre está jugándose la existencia.

No solamente el genio es frágil: el genio no puede criarse, el genio no tiene descendencia. "La breve duración de la belleza, del genio, del César, es sui generis: eso no se hereda. El tipo se hereda; un tipo no es nada extremo, no es un 'caso afortunado"' (Nietzsche, 2008: 14 [133], 569). La genialidad -esa capacidad de autoconfiguración máxima- adquiere el carácter de una monstruosidad afortunada dentro de la economía vital nietzscheana. En tanto caso afortunado, feliz, la genialidad opera como foco atractivo, figura que ilumina una trayectoria ascendente vital: la máxima autoproducción de poder. Pero en tanto monstruo -en tanto aislado, en tanto excepción no criable- no permite establecer una continuidad vital, no permite establecer una tipología. 
Ahora bien, esta vitalidad ascendente se contrapone, en lucha, con aquella perspectiva predominante de la época: la vitalidad en términos darwinianos. ¿En qué sentido Nietzsche despliega una postura anti-Darwin?

\section{Nietzsche y Darwin: adaptación, poder, teleología y excepcionalidad}

Nietzsche afirma:

Los fisiólogos deberían reflexionar antes de poner el impulso de conservación como impulso cardinal de los seres vivos orgánicos: ante todo, algo viviente quiere dejar salir su fuerza: la 'conservación’ sólo es una de las consecuencias de ello. ¡Cuidado con principios teleológicos superfluos! Y entre ellos está el entero concepto de 'impulso de conservación' (Nietzsche, 2007a: 24).

¿Critica Nietzsche aquí al impulso conservativo por teleológico o por superfluo? La remarcación del término 'superfluo' en lo recién citado se ve confirmada a partir del fragmento subsiguiente.

En esta victoria sobre el mundo y en esta interpretación del mundo a la manera de Platón había una especie de goce distinto al que nos ofrecen los fisiólogos de hoy, y asimismo los darwinistas y antiteleólogos entre los trabajadores de la fisiología, con su principio de la 'fuerza mínima' y la estupidez máxima. 'Allí donde el hombre no tiene ya nada que ver y agarrar, tampoco tiene nada que buscar', éste es, desde luego, un imperativo distinto del platónico [...] acaso sea el apropiado para una estirpe ruda y trabajadora [...] los cuales no tienen que realizar más que trabajos groseros (Nietzsche, 2007a: 25). 
Darwinistas y antiteleólogos, los estúpidos. En función de su imperativo -sensualista, aceptando solo la evidencia sensorial- es que ambos son incapaces de dar cuenta de la verdadera, la mayor potencia del viviente: aquella de sus fuerzas internas. Ante la noción del ser vivo como primariamente adaptativo al medio, Nietzsche dirá:

Anti-Darwin.- En lo que se refiere a la famosa 'lucha por la vida', a mí a veces me parece más aseverada que probada. Se da, pero como excepción; el aspecto de conjunto de la vida no es la situación calamitosa, la situación de hambre, sino más bien la riqueza, la exuberancia, incluso la prodigalidad absurda, -donde se lucha, se lucha por el poder... No se debe confundir a Malthus con la naturaleza.

Poniendo una vida pródiga en vez de una escasa en general, Nietzsche desarma el fundamento de la 'lucha por la vida'. No confundir a Malthus con la naturaleza: aquel escribe en 1789 An Essay on the principle of population, tratado económico donde asevera que hay una divergencia en el ritmo de crecimiento de la población humana y sus medios de subsistencia -geométrico el primero, aritmético el segundo- con lo cual se tiende a la escasez. Allí, Nietzsche explicita cómo en la lectura darwinista se transfiere tendenciosamente la perspectiva de la escasez económica humana a lo propio de la naturaleza misma.

Pero suponiendo que esa lucha exista $-\mathrm{y}$ de hecho se da-, termina, por desgracia, al revés de cómo lo desea la escuela de Darwin, al revés de como acaso sería lícito desearlo de ella: a saber, en detrimento de los fuertes, de los privilegiados, de las excepciones afortunadas (Nietzsche, 2007b: 95). 
La lucha por la existencia existe; el problema pasa por universalizarla, porque entonces se deja de lado el aspecto que Nietzsche busca resaltar: los fuertes, y también las excepciones afortunadas. El problema de la perspectiva darwinista no pasa así por el uso de un formato teleológico sino por la tendencia al empequeńecimiento vital que implica. El darwinismo, de hecho, no supone de por sí teleología alguna. Pichot marca que la selección natural darwiniana se despliega a partir de cuatro instancias: hay escasez de recursos para sustentar a la población, con lo cual se ha de luchar por su obtención; los miembros que son parte de una misma especie presentan caracteres variables; hay determinados caracteres que se presentan como ventajosos para la subsistencia en un determinado medio; vía herencia, esas ventajas producen nuevas especies (Cfr. Pichot, 1993: 790 y ss.). Como estipula Cano (2015: 58), si alguna de dichas instancias faltase la selección natural darwiniana no se daría; por ende, no existe una teleología propia de la postura de Darwin. ${ }^{4}$ ¿Por qué entonces Nietzsche la dispone como teleología?

Todo el mundo conoce el libro del célebre Cornaro, en que el autor recomienda la rigurosa dieta que él observaba para conseguir una vida larga y feliz al mismo tiempo que virtuosa. [...] Estoy convencido de que ningún libro (exceptuando la Biblia, por supuesto) ha hecho tanto daño ni ha abreviado tantas existencias como este singular engendro, escrito con buena intención, sin duda. El motivo es una confusión entre el efecto y la causa. Aquel buen italiano creía que su dieta era la causa de su longevidad, cuando lo que sucedía es que la condición primera para vivir mucho, la lentitud extraordinaria en la asimilación y desasimilación

\footnotetext{
${ }^{4} \mathrm{Al}$ respecto, Fornari sostiene incluso que Nietzsche era consciente de la vocación antiteleológica darwinista (2002: 100).
} 
y el escaso consumo de sustancias nutritivas eran, en realidad, la causa de su dieta (Nietzsche, 2007b: 46).

No es la dieta la que hace a Cornaro, sino a la inversa. Del mismo modo, no hay un algo 'natural' que haga a la selección natural, sino una tipología vital como presuposición que hace a lo 'natural' de la selección. Hacer la perspectiva económica malthusiana propia de la naturaleza misma dispone la 'naturalidad' del viviente como adaptación al medio. Exactamente eso es lo superfluo de la teología darwinista: no hay una naturaleza propia de lo vivo que tienda a la adaptación, sino un armado conceptual tendencioso -una valoración- puesto para justificar a la adaptación como teleología.

Desde la perspectiva de Nietzsche - perspectiva que al producir una inversión de términos (como en el caso de Cornaro) valora al discurso en función de sus efectos- resulta plenamente válido pensar a la mirada darwiniana como poseyendo una teleología superflua, y a su propia mirada como teleológicamente más valiosa: poner ambas miradas en términos de teleología permite dar cuenta que es el armado discursivo (sea científico u otro) el que está al servicio de un tipo de vida, y no al revés.

'Ironía ante lo que creen al cristianismo superado por las modernas ciencias naturales. Los juicios de valor cristianos no están en absoluto superados por ellas. "CCristo en la cruz' es el símbolo más sublime -aún hoy” (Nietzsche, 2008: 2[96], 104). La postura darwinista, exponente princeps de la perspectiva biológica moderna en la época de Nietzsche, no hace sino continuar con la valoración cristiana. Por su miopía conceptual -solo pueden ver lo que los sentidos les presentan- los darwinistas (y los antiteleólogos) solo verán lo que tienen enfrente, aquello que los valores cristianos les presentan como natural. Si el ser vivo es naturalmente adaptativo a las poderosas fuerzas externas, a aquello que el medio le impone, 
entonces -'naturalmente'- los valores del viviente habrán de ser los de humildad, sacrificio, culpa. Al ponerla en perspectiva teleológicamente, Nietzsche da cuenta de la mirada darwiniana como aquella que hace del núcleo del viviente algo esencialmente cristiano, pero dándole una cobertura cientificista, al invertir la relación causa-efecto y transferir la valoración de la dinámica poblacional humana, en términos económicos, a la naturaleza.

Ya sea desde la religión o la biología, de lo que se trata es de los valores desplegados: romper con el cristianismo será, desde Nietzsche, pensar una vida como voluntad de poder.

\section{La construcción discursiva: imposición e hibridación}

En su escrito de 1887 La genealogía de la moral, un escrito polémico, Nietzsche define al proyecto de la genealogía del siguiente modo:

Se trata de recorrer con preguntas totalmente nuevas y, por así decirlo, con nuevos ojos, el inmenso, lejano y tan recóndito país de la moral -de la moral que realmente ha existido, de la moral realmente vivida-: ¿y no viene esto a significar casi lo mismo que descubrir por vez primera tal país? (2000: 28-9).

La nueva mirada implica entonces reconfigurar el plano moral; como dirá Nietzsche: "necesitamos una crítica de los valores morales, hay que poner alguna vez en entredicho el valor mismo de esos valores" (2000: 28). Lo valores que desde la perspectiva cristiana se muestran como permanentes y sagrados -como verdades- son lo que, en tanto trascendentales, producen al hombre 'orgullo' y 'vanidad' (2003: 202). Algo totalmente distinto será la verdad para Nietzsche: 
¿Qué es entonces la verdad? Una hueste en movimiento de metáforas, metonimias, antropomorfismos, en resumidas cuentas, una suma de relaciones humanas que han sido realzadas, extrapoladas y adornadas poética y retóricamente y que, después de un prolongado uso, un pueblo considera firmes, canónicas y vinculantes; las verdades son ilusiones de las que se ha olvidado que lo son (2003: 358).

El proyecto de la genealogía supone así la ruptura con el carácter de verdad y trascendencia de los valores, proyectándolos hacia el continuo cambio de las interrelaciones humanas; al decir de Martínez Novillo: "la verdad se reinserta en el devenir" (2010: 17). ${ }^{5} \mathrm{Al}$ deshacer su trascendencia resulta posible el cuestionarlos, el filósofo tiene entonces que ocuparse de "solucionar el problema del valor, tiene que determinar la jerarquía de los valores" (2000: 71). La genealogía no se desenvolverá solamente en un movimiento hacia atrás, en donde se da cuenta del carácter no trascendente de la valoración, sino también habrá de proyectarse hacia delante, haciendo al valor algo construible, configurable en función de un proyecto.

Ahora bien, a lo largo de dicho proceso se genera lo que nominaremos como descentramiento en términos epistemológicos. El desenvolvimiento del proyecto genealógico no se da hacia dentro de un determinado campo epistemológico, sino que resulta transversal a un conjunto de ellos. Al abordar genealógicamente al concepto de culpa (Schuld) -ubicado por Nietzsche en el campo religioso-ético-, deriva al mismo del concepto de tener deudas, schulden (propio del espacio material de la legalidad y lo comercial) que proviene a su vez del placer producto del sufrimiento de

${ }^{5}$ Para un tratado más exhaustivo de dicho punto, cfr. Glenn (2004), como asimismo Gemes (1992), Hinman (1982) y Schacht (1984), entre otros. 
otro, propio de relaciones de dolor y placer; por ende, del campo fisio-psicológico (Cfr. Nietzche, 2000). De este modo, la configuración del valor supone el despliegue de relaciones heterodoxas seriadas a partir de una determinada conformación.

Ahora bien, esta modalidad configurativa no es privativa del valor: "La historia entera de una 'cosa', de un órgano, de un uso, puede ser así una ininterrumpida cadena indicativa de interpretaciones y reajustes siempre nuevos, cuyas causas no tienen siquiera necesidad de estar relacionadas entre sí [...]” (2000: 100). No solo los valores sino las 'cosas' en términos generales son resultado de interpretación desde múltiples instancias que no presentan necesidad conectiva; de este modo "no hay ningún acontecimiento en sí. Lo que sucede es un grupo de fenómenos escogidos y reunidos por un ser que interpreta” (2008: 1 [115], 60). Lo que hay no es entonces una mezcla arbitraria de instancias heterogéneas, sino una interpretación que configura y ordena de una determinada manera, deshaciendo sus sentidos anteriores y dándoles uno nuevo como parte de una determinada 'cosa'. Esto mismo se produce en términos de la dinámica vital como Wille zur Macht:

[1]a pasión dominante, la cual lleva consigo incluso la forma suprema de la salud en general: aquí se alcanza de manera óptima la coordinación de los sistemas internos y el concurso de sus trabajos al servicio de una unidad -pero, ¡esto es prácticamente la definición de la salud! (2008: 14[158], 584).

Esa modalidad constructiva -generadora de valores, conceptos, usos, vida- configura asimismo el campo del discurso nietzscheano: este incorpora instancias del campo de la biología (la categorización de anti-Darwin, entre otras), la fisiología (al dar cuenta de diversas dinámicas orgánicas referidas al desarrollo vital), de la psicología, el arte, la medicina, la historia, la filosofía, la filología. 
Esta combinación de instancias de diversos campos epistemológicos no es arbitraria u azarosa, sino que se produce en términos de lo que nominamos como descentramiento en términos epistemológicos. Así como las 'cosas' se configuran desde la interrelación y ordenamiento de elementos heterogéneos desde una perspectiva determinada, así como la construcción del concepto implica una transversalidad epistemológico-significativa en el devenir histórico -lo cual centralmente da cuenta de lo contingente propio de cualquier pertenencia epistémica- el propio campo discursivo de Nietzsche se configura como un conjunto de instancias epistemológicamente heterogéneas que son informadas de modo de -a la manera genealógica- producir nuevos sentidos desde una nueva modalidad de interrogación. De esta modalidad discursiva heterodoxa que rompe con una epistemología canónica depende que Nietzsche, a través de su obra, se nombre de múltiples maneras: es médico, psicólogo, filólogo, artista, filósofo...

Ahora bien, para que dicha multiplicidad no sea simple agregación o amontonamiento de elementos diversos, ha de imponerse una perspectiva que la ordene y configure, resignificándola. "El 'ser' -no tenemos para él otra representación ${ }^{6}$ más que 'vivir'-

${ }^{6}$ Quizá la utilización del término mediador 'representación' (Vorstellung) pueda conducir a la noción de que ese 'vivir' (erleben) resulta secundario o derivado respecto de ese 'ser' (Sein). Sin embargo, otro fragmento de esa época ilustra adecuadamente el sentido en que Nietzsche utiliza aquí 'representación': "Partiendo de una representación (Vorstellung) de la vida (que no es un quererconservarse sino un querer-crecer), he lanzado una mirada sobre los instintos fundamentales de nuestro movimiento político, espiritual y social en Europa" (2008, 2[179]: 131). La representación (Vorstellung) implica aquí entonces la perspectiva central, ordenadora, rectora a partir de la cual Nietzsche lanza su mirada: la vida como un querer-crecer. Como marcamos a lo largo de este apartado, la construcción de la 'cosa' implica este ordenamiento rector, y por ende, no hay nada por detrás de él: la 'cosa' 'es' a partir del ordenamiento producido desde la perspectiva rectora; así, al estipular Nietzsche que del ser no se tiene 
¿Cómo puede entonces 'ser' algo muerto?” (2008, 2 [172]: 130). Vivir (erleben) funge como la instancia a partir de la cual se hace posible el pensar el 'es' -así como a partir de una determinada perspectiva se da la configuración de la 'cosa'. Pensar a partir de la vida informa al campo discursivo nietzscheano, ordenando los diversos elementos epistemológicos que le son parte. De esta manera, al pensarse a sí mismo como médico lo hace en función del diagnóstico de debilitamiento de la cultura de Europa; se piensa como filósofo y aborda los valores desde lo que conduce a la elevación vital; se piensa como fisiólogo y da cuenta de la organicidad para la expansión de la vida; y se piensa como artista, poniendo a la potencia creativa como propia de lo activo de la vida misma.

La 'cosa' que es la discursividad nietzscheana despliega una multiplicidad epistemológica reconfigurada en función de una nueva perspectiva; una innovadora interrogación: ¿qué clase de vida es la que se busca desplegar?

\section{Bivalencia de la resignificación e hibridación: \\ la monstruosidad discursiva}

Nietzsche, habíamos dicho, marcaba lo siguiente respecto a la struggle for existence:

[p]ero suponiendo que esa lucha exista -y de hecho se da-, termina, por desgracia, al revés de cómo lo desea la escuela de Darwin, al revés de como acaso sería lícito desearlo de ella: a saber, en detrimento de los fuertes, de los privilegiados, de las excepciones afortunadas (Nietzsche, 2007b: 95).

otra representación (Vorstellung) que el vivir, está marcando que es a partir de la perspectiva del vivir que puede pensarse ese ser, o más bien, que no hay un ser por detrás de la perspectiva del vivir; por ende, no puede pensarse el ser de algo muerto. 
Lo lícito: aquello que representa la fortaleza desde la perspectiva darwinista es aquel que triunfa en la lucha por la supervivencia, a partir de su capacidad adaptativa al medio. Ese triunfo es la derrota desde el punto de vista de una vitalidad de la Wille zur Macht.

Los fuertes y privilegiados ya son pensados por Nietzsche en su primer obra publicada, El nacimiento de la tragedia; allí, refiriéndose a los griegos trágicos afirma: "el impulso, en lo que se refiere a la génesis de su creación, es precisamente la fuerza poderosa, positiva, creadora, y la razón es crítica: ¡verdadera monstruosidad! Pero en Sócrates el impulso se revela como crítico y la razón creadora: ¡verdadera monstruosidad per defectum!" (2000: 91). La monstruosidad propia de la génesis creativa será caracterizada luego como excepción afortunada -como genio-. Ahora bien: "La breve duración de la belleza, del genio, del César, es sui generis: eso no se hereda. El tipo se hereda; un tipo no es nada extremo, no es un 'caso afortunado'” (Nietzsche, 2008: 14 [133], 569). La genialidad no es hereditaria ni producto de crianza; es frágil y breve. En términos generales la vida responde así a tipologías, no a excepciones.

¿Qué sucede en Darwin con la excepcionalidad, con el monstruo? Se concibe en términos de individualidad cuyas variaciones resultan desfavorables para sobrevivir, y por ende no hay reproducción, o si la hay, el carácter excepcional no suele heredarse. ${ }^{7}$ De este modo, lo excepcional en Darwin tampoco se produce tipológicamente.

Si en cuanto a la imposibilidad de formación tipológica hay coincidencia respecto de la excepción en Darwin y Nietzsche, la valoración de la misma resulta radicalmente divergente. En

\footnotetext{
${ }^{7}$ Como Cano marca, los caracteres que Darwin otorga a las excepciones en $E l$ origen de las especies -especialmente los capítulos 1 y 2-son los de que "difieren en grado sumo", constituyen "saltos" y "excepciones", que representan "alguna considerable desviación (deviation) de conformación, que es perjudicial o inútil para la especie" (Cfr. 2015: 51-67).
} 
Darwin la excepción resulta completamente lateral para la dinámica general de la vida; en Nietzsche resulta central, en tanto no es sino la exacerbación misma del propio carácter de voluntad de poder. Así es que al respecto afirma:

[1]as mismas condiciones nuevas bajo las cuales surgirán, hablando en términos generales, una nivelación y una mediocrización del hombre -un hombre animal de rebaño útil, laborioso, utilizable y diestro en muchas cosas-, son idóneas en grado sumo para dar origen a hombres-excepción de una cualidad peligrosísima y muy atrayente (2007c: 175).

Desde este punto de vista, que pone en su centro al carácter valorativo del viviente -que lo piensa en términos teleológicos- en Nietzsche las condiciones propias de la dinámica vital han de desplegarse de forma no de producir excepcionalidad - pues la misma es sui generis- sino de resultar favorables para permitir su desarrollo.

En términos del carácter epistemológico general, ¿cómo es concebida la discursividad nietzscheana? Ya en El nacimiento de la tragedia en el espiritu de la música (Die Geburt der Tragödie aus dem Geiste der Musik) de $1872,{ }^{8}$ al analizar la aparición y fin del modelo artístico propio de la tragedia ática, el abordaje de Nietzsche rompe de modo determinante con la perspectiva canónica epocal. En ese mismo año Ulrich von Wilamowitz-Möllendorf, renombrado filólogo, realiza una crítica lapidaria a la perspectiva nietzscheana; ¡Filología del futuro! Una respuesta a de 'El nacimiento de la tragedia' de Friederich Nietzsche (Zukunftsphilologie! Eine Erwiderung auf Friederich Nietzsches 'Geburt der Tragödie') es el panfleto en el

\footnotetext{
${ }^{8}$ Reeditado en 1886 con el nombre de El nacimiento de la tragedia o Helenismo y pesimismo (Die Geburt der Tragödie, Oder: Griechentum und Pessimismus).
} 
cual centralmente destaca la incompatibilidad y peligro de lo dicho por Nietzsche para con las bases mismas del pensar racional y, entonces, para la filología en su totalidad, epistemológicamente hablando. En relación a dicha obra nietzscheana Porter marca que Wilamowitz-Möllendorf encuentra allí un agregado de

mitología griega, musicología y filosofía schopenhaueriana, que carecía de los signos típicos de los estudios clásicos: no había notas al pie, ni citas de fuentes griegas originales y un solo pasaje traducido (unos pocos versos de Sófocles), no había citas de fuentes primarias, ni referencias a estudios clásicos de ningún tipo. $\mathrm{Ni}$ siquiera su narrativa podía ser reducida a las tramas familiares de libros de texto antiguos o modernos [...] (2011: 73).

Desde nuestra perspectiva analítica se está -ya desde la primera obra nietzscheana- frente a la hibridación propia de la excepción nietzscheana: una multiplicidad de instancias epistemológicamente heterogéneas reconfiguradas a partir de una perspectiva ordenadora que, de modo bivalente, genera un campo de discurso en ruptura respecto a la epistemología canónica. Nietzsche incorpora instancias filosóficas, mitológicas, artísticas, filológicas, resignificándolos en función de la pregunta por el pesimismo vital helénico y el optimismo socrático. Ingresando en esos espacios epistemológicos, toma partes y configura un espacio nuevo desde una perspectiva: la vida helénica, su cultura y la transformación de la misma. De este modo, resignificación y configuración de nuevo espacio de discurso se implican bivalentemente: solo dándose uno se da el otro.

Ahora bien, ¿cómo es posible tomar elementos de distintos ámbitos epistemológicos y reconfigurarlos discursivamente? Dicho de otro modo: si dichos elementos pertenecen a lógicas de campos epistemológicos diversos, ¿cómo es posible que se produzca un or- 
denamiento resignificante y no una simple acumulación que devenga en pura mezcla?

Para dar cuenta de ello, realicemos un análisis discursivo del fragmento nietzscheano sobre la struggle for existence darwinista:

[a]nti-Darwin.- En lo que se refiere a la famosa 'lucha por la vida', a mí a veces me parece más aseverada que probada. Se da, pero como excepción; el aspecto de conjunto de la vida no es la situación calamitosa, la situación de hambre, sino más bien la riqueza, la exuberancia, incluso la prodigalidad absurda, -donde se lucha, se lucha por el poder... No se debe confundir a Malthus con la naturaleza. -Pero suponiendo que esa lucha exista $-y$ de hecho se da-, termina, por desgracia, al revés de cómo lo desea la escuela de Darwin, al revés de como acaso sería lícito desearlo de ella: a saber, en detrimento de los fuertes, de los privilegiados, de las excepciones afortunadas (2007d: 95).

La dinámica nietzscheana parece presentar en el fragmento un carácter progresivo: avanzar desde el propio campo de discurso de Darwin hasta llegar al suyo. Comienza reemplazando la escasez de la naturaleza por un carácter pródigo; en tanto si lo que hay es riqueza de recursos la lucha por la supervivencia pierde su razón de ser, ese reemplazo es del orden argumentativo, en términos de refutación. Ahora bien, como Nietzsche establece (respecto a un libro de Paul Reé):

[e]n la obra antes mencionada [...] me referí con ocasión y sin ella, a las tesis de aquél, no refutándolas -iqué me importan a mí las refutaciones!- sino, cual conviene a un espíritu positivo, poniendo, en lugar de lo inverosímil, algo más verosímil, y en lugar de un error, otro distinto (2000: 25). 
La discursividad nietzscheana no se despliega así desde la refutación, en tanto la estructura argumental de la refutación implica la noción de la conceptualidad en sí, contraria a la de concepto como construcción. El desplegar la relación de escasez-abundancia de recursos en términos de refutación busca dar cuenta del carácter artificioso de la misma; como se había mencionado, que 'no se debe confundir a Malthus con la naturaleza' implica la explicitación del traslado tendencioso de una perspectiva económica humana al carácter de la naturaleza misma, para así naturalizar una determinada interrelación entre medio y viviente. Al explicitar dicho carácter artificioso -y, por ende, mostrarlo como construcción- Nietzsche desplaza la confrontación hacia su propio campo conceptual, para dar cuenta de que el constructo argumental darwiniano da como resultado una vida empequeñecida. Esto último que desde la perspectiva de Darwin resulta un efecto de la lucha por la supervivencia, es desde Nietzsche la causa: la perspectiva de la naturaleza escasa en recursos está allí como justificación de la ya presupuesta struggle for existence.

La construcción conceptual teleológica nietzscheana está allí justamente para dejar en evidencia esto mismo: la vida como adaptación no es consecuencia de las condiciones del medio, sino que se produce un armado conceptual artificioso respecto del medio para justificar que esa sea la perspectiva vital preponderante.

Lo esencial no resulta entonces la construcción conceptual-argumentativa respecto a una perspectiva sobre la vida, sino la clase de vitalidad desde la que se configura dicha construcción: ${ }^{9}$ una vida que prepondera al adaptarse, o una que tienda al plus de poder. $^{10}$

${ }^{9} \mathrm{Y}$ esto es justamente lo que significa Nietzsche al decir que no le importan las refutaciones, sino poner algo más verosímil donde había algo menos.

${ }^{10}$ En este sentido es posible tomar la afirmación de Glenn: "la epistemología es un tema moral, y por tanto es un terreno de lucha clave en el conflicto entre los 
Para poner la perspectiva darwiniana como teleológicamente enfrentada a la propia, Nietzsche primeramente ha de reconfigurar la conceptualidad de Darwin en términos constructivos -dando cuenta del trasvasaje Malthus/naturaleza. Así, la dinámica discursiva no pasa por tomar un elemento e insertarlo entre otros, sino que al pasaje de un campo discursivo al otro le corresponde una labor de progresiva reconfiguración del mismo -y entonces, resignificación y construcción discursiva híbrida presentan una relación bivalente.

La crítica de Wilamowitz-Möllendorf respecto a Die Geburt der Tragödie, como se había marcado, ponía en un primer plano el peligro que la discursividad nietzscheana suponía para los fundamentos de lo racional mismo -siendo corolario de esto el ataque a la filología clásica ${ }^{11}$. Respecto de esto último, en efecto, el campo de discursividad híbrida implica no solo el romper con modalidades epistemológicas concretas, sino con la noción misma de epistemología canónica en cuanto tal. No se trata de un nuevo campo discursivo científico y/o filosófico canónico, sino una configuración por fuera del mismo. La crítica de Wilamowitz-Möllendorf no se da porque las ideas nietzscheanas innoven o incluso vayan en contra de lo sostenido en el campo filológico, sino porque atentan contra las bases de la construcción epistemológica en sí: se interrelacionan instancias que no pueden ser articuladas desde la lógica de la epistemología canónica. ${ }^{12}$ De este modo la obra nietzscheana

fuertes y los débiles" (2004: 577).

${ }^{11}$ Para una ampliación del tema cfr. Porter (2011), Calder (1983), Sweet (1999) y Mansfeld (1986), entre otros.

${ }^{12} \mathrm{Al}$ respecto, vale notar cómo Sánchez Meca (2019) refiere a la fusión nietzscheana entre filosofía y teatro, que supone una ruptura con el canon discursivo filosófico; asimismo, Gimber (2019) y Lesmes (2019) hablan de cómo dicha ruptura con el canon es retomada, desde el arte, por el movimiento vanguardista; en esta línea, Roldán López (2019) marca que desde la lectura contemporánea de Nietzsche comienza a complicarse hablar de ciertos géneros artísticos; ya 
no es una construcción errada, corregible, subsanable: es anti-epistemológica, está por fuera de lo científico.

Ahora bien, que la labor nietzscheana sea anti-epistemológica ¿la hace anti-racional?

Desde el punto de vista de Wilamowitz-Möllendorf, sí; aquí es posible retomar la crítica que Nietzsche hace a los antiteleólogos y darwinistas: la miopía conceptual. Wilamowitz-Möllendorf deduce de la evidente ruptura para con la modalidad filológica clásica presente en el escrito de Nietzsche -caracterizada en la cita anterior de Porter- el carácter contrario a lo racional de dicho escrito, ${ }^{13}$ lo cual es posible solo si se toma a la epistemología clásica subyacente al canon filológico como el producto natural de la racionalidad científica. Ahora bien, la discursividad nietzscheana no es contraria a lo racional: como da cuenta el análisis del fragmento relativo a la struggle for existence, lo que allí se produce es el despliegue de un por-fuera de la epistemología canónica, a través de una progresiva transformación de correspondencia bivalente entre resignificación y construcción de discurso híbrido. El discurso se dispone de\} «sde otra perspectiva, a través de la pregunta por el tipo de vida que se quiere, y desde aquí denuncia a la epistemología clásica por invertir las relaciones de causa y efecto. Así como en Darwin lo presupuesto es la vida adaptativa y la consecuencia es la correspondiente construcción discursiva de tinte científico, en Wilamowitz-Möllendorf puede decirse que lo presupuesto es la construcción epistemológica canónica, y la consecuencia es un determinado recorte de lo que la racionalidad es. Debido a la mis-

no puede solo hablarse de danza, sino también de danza-teatro; no solo de artes, sino de artes performativas.

${ }^{13}$ De hecho, lo habíamos presentado de modo inverso: Wilamowitz-Möllendorf piensa a la obra de Nietzsche como contra lo racional y, por ende, contra la filología. Pero esto obedece justamente a la inversión de causa y consecuencia de la que habla Nietzsche, como a continuación se detallará. 
ma miopía conceptual que padecen tanto uno como el otro, en el caso de Wilamowitz-Möllendorf epistemología y racionalidad se hallan soldados de ese modo; por ende, si Nietzsche rompe con la filología clásica rompe con lo racional mismo. Desde el punto de vista de Nietzsche, de lo que se trata es de romper no con la noción de struggle for existence ni con la epistemología clásica en sí, sino con aquello que estas presuponen: el recorte de lo que es la racionalidad en el caso de Wilamowitz-Möllendorf (que lleva a considerar como válida una única manera de construir discurso) y la vida adaptativa en Darwin (que implica la pérdida de las fuerzas activas y la capacidad de luchar por el poder).

La discursividad nietzscheana cobra así el carácter de genio en tanto monstrum: lo excepcional, lo sui generis, pero también lo frágil; desde el punto de vista de la excepcionalidad darwiniana, también lo dejado de lado por lo preponderante (por lo que tiene éxito en la supervivencia). En su juventud se consideraba a Nietzsche como alguien con un gran futuro en la filología (fue quien más joven obtuvo el cargo de profesor en Basilea). Tras el conflicto con Wilamowitz-Möllendorf resulta progresivamente dejado de lado en el ámbito académico, hasta abandonar su cargo. ${ }^{14}$ Sus escritos son recibidos positivamente en algunos ámbitos, pero no por su perspectiva filosófica sino en carácter de poesía o literatura, ${ }^{15}$ al menos no hasta los cursos que dicta Heidegger. La obra nietzscheana es así puesta en un lugar periférico, sin valorarse

${ }^{14} \mathrm{Si}$ bien la causa oficial es la de una licencia médica -Nietzsche era efectivamente un enfermo crónico- se aducen múltiples razones por el abandono de su puesto, entre las cuales está por supuesto el aislamiento académico y la mala recepción de sus ideas. En este sentido se pronuncian Grimber y Sancho Vich (2019) al marcar que Richter, amigo de Nietzsche, le recomienda no publicar El nacimiento hasta no haber solidificado su posición en la academia. Para ahondar, cfr. la conocida biografía de Rüdiger Safranski Nietzsche. Biografía de su pensamiento (2000), entre otras.

${ }^{15}$ Como caso paradigmático, según marca Grimber (2019), aparece el Zarathustra. 
como filosófica, y por fuera del status quo epistemológico. Tanto el darwinismo como la perspectiva de Wilamowitz-Möllendorf-que se pone como el defensor del canon- implican la expulsión de lo excepcional como monstruoso. Pero -en una revalorización del monstruo- la perspectiva nietzscheana piensa las condiciones de nivelación y mediocrización generales como idóneas para el surgimiento de la excepción. ${ }^{16}$ Así, en la dinámica del genio -que implica una yuxtaposición de enfermedad y tendencia al plus de poder- aquello que hace enfermo desde el punto de vista canónico al discurso nietzscheano -la hibridación, la multiplicidad ilegítima de conexiones epistemológicas- es lo que hace propender al plus de poder, en la forma de una perspectiva vital que se impone y ordena todos esos elementos. Desde la periferia, Nietzsche busca confrontar con los discursos preponderantes del momento, enfrentándose no solo con la perspectiva darwinista, ${ }^{17}$ sino con el modo mismo de construcción de discurso de la ciencia. De este modo la discursividad nietzscheana no es a-racional, sino constituyente de una otra racionalidad fundamentalmente disruptiva para con la epistemología clásica: produce una perspectiva que dispone la construcción del discurso desde otro lugar -aquel de la pregunta por el tipo vital- y desde allí busca desplegarse a la moral, lo científico, lo cultural mismo. En la modalidad de lectura nietzscheana -desde la inversión de causa y efecto- las miradas de Darwin y Wilamowitz-Möllendorf apuntan a lo mismo: denegar una pers-

${ }^{16}$ En esta línea, resulta válido remarcar lo que Quejido López (2019) menciona respecto a cómo, en términos artísticos, la ruptura rítmica respecto a los cánones musicales produce según Nietzsche el surgimiento de la excepcionalidad. ${ }^{17}$ Nietzsche mismo piensa el extender la Wille zur Macht más allá del registro vital: "La voluntad de acumular fuerza como específica para el fenómeno de la vida, para la nutrición, la reproducción, la herencia [...] ¿No deberíamos tener el derecho de admitir esa voluntad como causa motora incluso de la química? ¿Y en el orden cósmico?” (2008: 14 [81], 535). 
pectiva que pone a la excepcionalidad como ruptura de los valores de una racionalidad pequeña, descendente.

\section{Bibliografía}

Alvarez, María y Aaron Ridley, 2005, "Nietzsche on Language: Before and After Wittgenstein", Philosophical Topics, vol. 33, núm. 2, pp. 1-17.

Ansell-Pearson, Keith, 1992, "Who is the Übermensch? Time, Truth and Woman in Nietzsche", Journal of the History of Ideas, vol. 53, núm. 2, pp. 309-331.

Assoun, Paul-Laurent, 2008, Freud et Nietzsche, P.U.F, París.

Barcalett Pérez, María, 2006, Friedrich Nietzsche: la vida, el cuerpo la enfermedad, Universidad Autónoma del Estado de México, México.

Calder, William, 1983, "El debate Wilamowitz-Nietzsche: nuevos documentos y una reevaluación”, Nietzsche-Studien, vol. 12, pp. 214-54.

Cano, Virginia, 2015, "Is evolution blind? On Nietzsche's reception of Darwin", en Nietzsche and the Becoming of Life, Fordham University Press, Nueva York, pp. 51-67.

Cragnolini, Mónica, 1998, Nietzsche, camino y demora, Eudeba, Buenos Aires.

Drivet, Leandro, 2015, "Freud como lector de Nietzsche. La influencia de Nietzsche en la obra de Freud", Civilizar, vol. 15 núm. 2, pp. 197-214.

Emden, Christian, 2005, Nietzsche on Language, Consciousness, and the Body, University of Illinois Press, Illinois.

Fornari, María, 2002, "Nietzsche and darwinism", Journal of Nietzsche Studies, núm. 23, pp. 89-125. 
Gemes, Ken, 1992, "Nietzsche's Critique of Truth”, Philosophy and Phenomenological Research, vol. 52, núm. 1, pp. 47-75.

Gerhardt, Volker, 2002, "La gran razón del cuerpo. Un ensayo sobre el Zarathustra de Nietzsche", Enrahonar, núm. 35, pp. $31-43$.

Gimber, Arno y Carlos Sancho Vich, 2019, "Modelos literarios en la obra de Nietzsche", conferencia del 1er congreso de la RIEN (Red Interamericana de Estudios Nietzscheanos), Goethe Institut de Madrid. Disponible en: https://www.youtube.com/ watch?v=ZNA3ZGQhTLM\&ab_channel=OscarQuejido

Gimber, Arno, 2019, "La máscara y el rito: Nietzsche y el teatro posdramático", conferencia del 1er congreso de la RIEN (Red Interamericana de Estudios Nietzscheanos), Goethe Institut de Madrid. Disponible en: https://www.youtube.com/ watch?v=u0wqUwB5rIk\&ab_channel=RedNietzsche

Glenn, Paul, 2004, "The Politics of Truth: Power in Nietzsche's Epistemology", Political Research Quarterly, vol. 57, núm. 4, pp. 575-583.

Halévy, Daniel, 1943, La vida de Friedrich Nietzsche, Emecé, Buenos Aires.

Hanza, Kathia, 2003, "Nec docere neque delectare sed sublimare. Sobre la metáfora de la literatura como sublimación en Freud y Nietzsche", Estudios de filosofia, núm. 28, pp. 35-54.

Hinman, Lawrence, 1982, "Nietzsche, Metaphor and Truth", Philosophy and Phenomenological Research, vol. 43, núm. 2, pp. 179-199.

Daniel Lesmes, Daniel, 2019, "Nietzsche y el retorno en la vanguardia", conferencia del 1er congreso de la RIEN (Red Interamericana de Estudios Nietzscheanos), Goethe Institut de Madrid. Disponible en: https://www.youtube.com/ watch?v=7VrP_14aQqg\&ab_channel=OscarQuejido 
Lichttemberger, Henri, 1923, La philosophie de Nietzsche, Lib. Félix Alcam, París.

Mansfeld, James, 1986, "The Wilamowitz-Nietzsche struggle: Another new document and some further comments", Nietzsche Studien, núm. 15, pp. 41-58.

Lucero, Guadalupe, 2007, "Música insignificante. Avatares de la insistencia musical en la crítica nietzscheana del lenguaje", Instantes y Azares, Escrituras Nietzscheanas, núms. 4-5, pp. 67-82.

Martínez Novillo, Javier, 2010, "Genealogía y discurso. De Nietzsche a Foucault", Nómades. Revista de Ciencias Sociales y Jurídicas, vol. 13, pp. 16-38.

Niemeyer, Charles, 2012, Diccionario Nietzsche. Conceptos, obras, influencias y lugares, Siglo XxI, Madrid.

Nietzsche, Friedrich, 1999, Aurora, Alba, Barcelona.

,2000, Genealogía de la moral, Alianza, Madrid.

,2003, Sobre verdad y mentira en sentido extramoral, Península, Madrid.

,2007a, El nacimiento de la tragedia, Alianza, Madrid.

, 2007b, Así habló Zarathustra, Alianza, Madrid.

, 2007c, Más allá del bien y del mal, Alianza, Madrid.

, 2007d, El crepúsculo de los idolos, Alianza, Madrid.

, 2008, Fragmentos Póstumos, Tecnos, Madrid.

Onfray, Michael, 2012, Nietzsche contra Freud, Taurus, Madrid.

Pichot, André, 1993, Histoire de la notion de vie, Gallimard, París.

Porter, James, 2011, “'Don't Quote Me on That!': Wilamowitz Contra Nietzsche in 1872 and 1873", Journal of Nietzsche Studies, vol. 42, núm. 1, pp. 73-99. 
Quejido Alonso, Oscar, 2019, "Ritmo y librepensamiento: el tempo del arte y de lo excepcional", conferencia del 1er congreso de la RIEN (Red Interamericana de Estudios Nietzscheanos), Goethe Institut de Madrid. Disponible en: https:/www.youtube.com/watch?v=xaDBwdw3bIg\&ab_channel=RedNietzsche

Rawat, Khalid, 2013, "Language and Truth: a Study of Nietzsche's Theory of Language”, Annales Philosophici, núm. 6, pp. 39-46.

Reginster, Bernard, 2006, The affirmation of life: Nietzsche on overcoming nibilism, Harvard University Press, Cambridge.

Roldán López, Carlos, 2019, "La danza en Nietzsche: el lenguaje lúdico de la voluntad de poder", conferencia del 1er congreso de la RIEN (Red Interamericana de Estudios Nietzscheanos), Goethe Institut de Madrid. Disponible en: https:/www.youtube.com/watch?v=4BVFHiC_nvy\&ab_channel=OscarQuejido

Safranski, Rüdiger, 2001, Nietzsche. Biografía de su pensamiento, Tusquets, Barcelona.

Schacht, Richard, 1984, "Nietzsche on Philosophy, Interpretation and Truth", Nô̂s, vol. 18, núm. 1, pp. 75-85.

Steineger, José, 2004, "Friederich Nietzsche and Sigmund Freud failure: a tomist protest on truth", Quodlibet Diary, vol. 6 núm. 1, pp. 24-39.

Stiegler, Barbara, 2001, Nietzsche et la biologie, puf, París.

,2003, “¿Qué cambia poner el cuerpo en el lugar del alma? Nietzsche entre Descartes, Kant y la biología”, Eidos, núm. 1, pp. 128-141.

Strong, Tracy, 1976, "Language and Nihilism: Nietzsche's Critique of Epistemology", Theory and Society, vol. 3, núm. 2, pp. 239-263.

Sokel, Walter, 2005, "On the Dionysian in Nietzsche”, New Literary History, núm. 36, pp. 501-520. 
Sweet, Denis. 1999, "The Birth of 'The Birth of Tragedy", Journal of the History of Ideas, vol. 60, núm. 2, pp. 345-359.

Van Tongeren, Paul, et al., 2001, "Hors D’Oeuvre: Nietzsche's Language and Use of Language", Journal of Nietzsche Studies, núm. 22, pp. 5-16.

Vattimo, Gianni, 2002, Diálogo con Nietzsche, Paidós, Buenos Aires.

Yadin, Azzan, 2001, "A Web of Chaos: Bialik and Nietzsche on Language, Truth, and the Death of God", Prooftexts, vol. 21, núm. 2, pp. 179-203. 